\title{
NUMERICAL COMPUTATION OF LAMINAR NATURAL CONVECTION IN TRIANGULAR SHAPED CAVITIES
}

\author{
EMIN FUAD KENT \\ İTU Istanbul Technical University Mechanical Engineering Faculty, Turkey
}

\begin{abstract}
In the present work, a numerical analysis of laminar natural convection in right and isosceles triangular enclosures has been carried out. Two dimensional, steady-state governing equations (conservation of mass, momentum and energy) were solved in Cartesian coordinates by the finite volume method. Several configurations are examined over a range of Rayleigh numbers that ranged from $10^{3}$ to $10^{5}$; for cavity walls that are heated, cooled or insulated. Streamlines and isotherms are displayed as streamline plots and isotherm lines for various triangular enclosures and, for Rayleigh number ranged from $10^{3}$ to $10^{5}$ with heated from the bottom. The effect of the aspect ratio, that is taken as a parameter, on the convective flow and isothermal contours in the triangular cavity are examined in detail. Symmetry breaking pitchfork bifurcations and multicellular flow structures and their effects on temperature distributions at low aspect ratios and high Rayleigh numbers are inspected. The overall heat transfer capabilities of the isosceles triangular enclosures are evaluated and assessed by examining the average convective Nusselt numbers.
\end{abstract}

Keywords: natural convection, triangular shaped cavity, finite volume method, Rayleigh number, Grasshof number, Nusselt number, numerical methods, isosceles triangular cavity, right triangular cavity.

\section{INTRODUCTION}

Lots of the previous works about natural convection are based on the analysis of square and rectangular or cylindrical enclosures as these are commonly used in real life applications. Natural convection analyses in buildings, heat isolation systems and solar energy applications are usually about square and rectangular or rectangular like enclosures. For this reason, there are a lot of studies that focused on these type of enclosures with different thermal boundary conditions and dimensions. As the enclosures in applications are not always in rectangular and cylindrical shapes, natural convection in other types of geometries should necessarily be studied. A considerable increase in the number of published papers devoted to triangular cavities has been noticed in the recent literature. This subject has practical applications in domestic and industrial fields, for instance, heat transfer in triangular shaped roofs (attic), triangular solar stills and collectors, and natural convective cooling of electronic equipment and geophysical applications.

The pioneering works about in triangular shaped cavities were made by Flack [1], Flack et al. [2] and Flack [3]. Akinsete and Coleman [4] carried out a numerical analysis on this subject in right triangular cavities. Poulikakos and Bejan [5] theoretically and numerically examined the same phenomenon in right triangle shaped channels heated from the bottom. Considering symmetry for an isosceles triangular enclosure, Salmun [6], [7] examined a right triangular enclosure with symmetry condition. On the other hand, Holtzman et al. [8] adopted the finite element method to simulate the complete isosceles triangular enclosure without symmetry condition. Lei et al. [9] analysed unsteady natural convection of water in triangular enclosures instead of air. Kent [10] examined the similar subject for isosceles triangular shaped roofs (attics) with bottom heating. In another work, Kent [11] analysed the specific case of the same subject, but this time for top heated cavities. The similar subject in in right triangular enclosures was searched by Kent et al. [12]. Wang et al. [13] worked natural 
convection flow in various enclosures including square, isosceles and right triangle for different boundary conditions. A comparison of the heat transfer results for rectangular and triangular cavities were realized. Triveni and Panua [14] focused on the influence of different geometrical configuration of the bottom wall of a right triangular cavity on flow and heat transfer rate. Further works on this subject may be found in the review studies given below and the references therein.

In addition to these works, some review studies devoted to natural convection flow and heat transfer in the enclosures of various types have been seen in the recent literature. Rahimi et al. [15] carried out a review of the latest works on this subject. Square and rectangular enclosures, trapezoidal, triangular and parallelogram shape enclosures with different physical and thermal boundary conditions, governing parameters and fluids (fluid and nano-fluid media) were considered and their effects on convective flow and heat transfer performance were thoroughly analysed. Bairi et al. [16] made a review on natural convection in important cavity shapes from the point of view of engineering applications. It must be noted that this review was principally devoted to the parallelogram-shaped cavity. In another review, Das et al. [17] summarized the works about flow in triangular, trapezoidal, parallelogram-shaped enclosures or also nano-fluid filled enclosures. Oztop et al. [18] review on this subject mainly focuses on the type and locations of the local heat source. Another review of studies devoted to triangular enclosures was performed by Kamiyo et al. [19]. In this work, experimental procedures and numerical simulations concerning natural convection in triangular enclosures were reviewed. Saha and Khan [20] made a review of works on natural convection heat transfer in attic-shaped buildings, and also studies related to this subject. All the abovementioned works assumed two-dimensional flow in the cavity. Three-dimensional numerical analysis of natural convection and entropy generation in an air filled triangular cavity with inserted isothermal heater at the bottom wall has been given in Aich [21] very recently. It must be noted that the width of the cavity (the third dimension) is equal to the half of the semi-length cavity. Another recent work using three-dimensional numerical modelling of transient free convection and heat transfer in a section-triangular prismatic enclosure with different (depth-width) aspect ratios has been conducted by Cui et al. [22]. In their study, the width of the cavity (the third dimension) is equal to the semi-length of the cavity. In these narrow cavities, the end-walls substantially affect the flow structure and thus the transverse rolls and longitudinal rolls occur in the cavity. These flow structures determined by the depth ratio and the Rayleigh number have been characterized based on three-dimensional numerical results. On the other hand, majority of the works have been devoted to laminar flow regime and comparatively less studies considered transitional or weakly turbulent flows. Hease and Teubner [23] put the order of the Rayleigh number at $10^{10}$ and $10^{11}$. They investigated this range for bottom heating but do not apply turbulence modelling. Ridouane et al. [24] analysed numerically two-dimensional turbulent natural convection in an air filled isosceles triangular enclosure using a low-Reynolds-number k- $\varepsilon$ model for a range of Ra values between $10^{9}$ and $10^{10}$. Talabi et al. [25] numerically investigated time dependent, two-dimensional low turbulence natural convection of air contained in the attic of a pitched roof of triangular crosssection using differential Reynolds stress turbulence model for Rayleigh number ranged from $10^{9}$ to $10^{11}$.

\section{PROBLEM DEFINITION}

The geometric configuration of the systems for isosceles and right triangular enclosures are shown in Fig. 1. The walls of the triangular enclosures are maintained hot, cold or insulated. The aspect ratio $\mathrm{A}$ is defined as the height $(\mathrm{H})$ to the full length of base $(\mathrm{B})$ ratio for isosceles triangle; and the height $(\mathrm{H})$ to the base length $(\mathrm{L})$ ratio for right angle enclosure. Two- 
dimensional flow is assumed in this study just like the most of the previous works on this subject. The third dimension of the cavity is considered long enough for the flow to be considered 2D. It must be noted here that three-dimensional numerical analysis of this problem for narrow cavities is under study and is the subject of a future work.

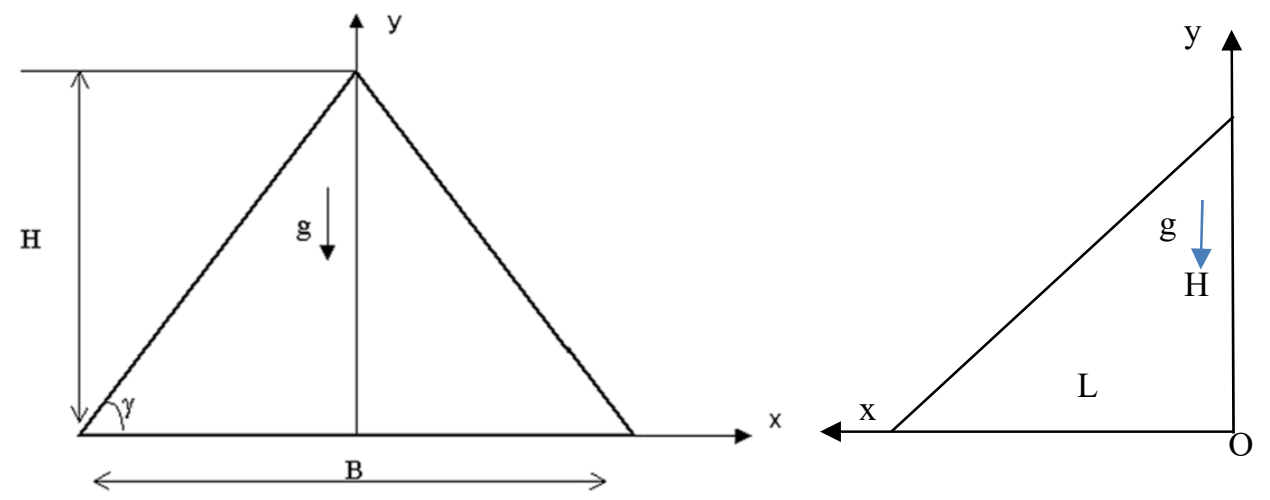

Figure 1: The schematic of the isosceles and right triangular enclosures.

The following simplifying assumptions are made for the ensuing analysis:

1. Flow is laminar and two dimensional. In order to be within the limits of laminar flow regime, the Rayleigh number of the flow is ranged from $10^{3}$ to a maximum of $10^{5}$ in this work. So the assumption of laminar flow is justified. It is worth mentioning that many works assume laminar flow at much higher Rayleigh numbers greater than $10^{5}$ in the literature and do not apply any turbulence modelling. Numerical analysis of the flow structure and heat transfer at high Rayleigh numbers for the same problem using turbulence modeling is also the subject of another work.

2. Viscous dissipation can be neglected.

3. There is no heat source or sink inside the enclosures.

4. The Boussinesq approximation is assumed to be valid. Thus the variation in density is neglected everywhere except in the buoyancy term. It is worth mentioning that Gray and Giorgini [26] examined the applicability of this approximation. For air, this approach may be used for maximum temperature difference less than $28.6 \mathrm{~K}$. In this work, in order to guarantee this maximum temperature difference limits, the temperature of the walls, are maintened at 303 and $283 \mathrm{~K}$, respectively.

Under the aforementioned approximationes, the steady-state form of the conservation equations can be written as Das et al. [17]

$$
\begin{gathered}
\frac{\partial u}{\partial x}+\frac{\partial v}{\partial y}=0 \\
u \frac{\partial u}{\partial x}+v \frac{\partial u}{\partial y}=-\frac{1}{\rho} \frac{\partial p}{\partial x}+v\left(\frac{\partial_{2} u}{\partial x_{2}}+\frac{\partial_{2} u}{\partial y_{2}}\right) \\
u \frac{\partial v}{\partial x}+v \frac{\partial v}{\partial y}=-\frac{1}{\rho} \frac{\partial p}{\partial y}+v\left(\frac{\partial_{2} v}{\partial x_{2}}+\frac{\partial_{2} v}{\partial y_{2}}\right)+g \beta\left(T-T_{c}\right)
\end{gathered}
$$




$$
u \frac{\partial T}{\partial x}+v \frac{\partial T}{\partial y}=\alpha\left(\frac{\partial_{2} T}{\partial x_{2}}+\frac{\partial_{2} T}{\partial y_{2}}\right)
$$

Velocities, on all walls:

- $\mathrm{u}=\mathrm{v}=0$,

and temperatures:

- $\quad \mathrm{T}=\mathrm{T}_{\mathrm{H}}$ on hot;

- $\quad \mathrm{T}=\mathrm{T}_{\mathrm{C}}$ on cold walls.

Here, $u$ and $v$ denote the velocity components in Cartesian coordinates, $T$ stands for the temperature, $v$ and $\alpha$ are kinematic viscosity and thermal diffusivity, respectively. $\rho$ and $p$ and $\beta$ are density, pressure, and the coefficient of thermal expansion, respectively. $g$ is the acceleration of gravity. $\mathrm{T}_{\mathrm{H}}$ and $\mathrm{T}_{\mathrm{C}}$ stand for the temperature at the hot wall and the temperature at the hot wall, respectively.

Using

$$
\begin{gathered}
X=\frac{x}{H}, \quad Y=\frac{y}{H}, \quad U=\frac{u H}{\alpha}, \quad V=\frac{v H}{\alpha}, \quad \theta=\frac{T-T_{C}}{T_{H}-T_{C}}, \\
P=\frac{p H_{2}}{\rho \alpha_{2}}, \quad \operatorname{Pr}=\frac{v}{\alpha}, \quad R a=\frac{g \beta\left(T_{H}-T_{C}\right) H_{3}}{v \alpha},
\end{gathered}
$$

the conservation equations can be written in non-dimensional form:

$$
\begin{gathered}
\frac{\partial U}{\partial X}+\frac{\partial V}{\partial Y}=0 \\
U \frac{\partial U}{\partial X}+V \frac{\partial U}{\partial Y}=-\frac{\partial P}{\partial X}+\operatorname{Pr}\left(\frac{\partial_{2} U}{\partial X_{2}}+\frac{\partial_{2} U}{\partial Y_{2}}\right), \\
U \frac{\partial V}{\partial X}+V \frac{\partial V}{\partial Y}=-\frac{\partial P}{\partial Y}+\operatorname{Pr}\left(\frac{\partial_{2} V}{\partial X_{2}}+\frac{\partial_{2} V}{\partial Y_{2}}\right)+\operatorname{Ra} \operatorname{Pr} \theta \\
U \frac{\partial \theta}{\partial X}+V \frac{\partial \theta}{\partial Y}=\frac{\partial_{2} \theta}{\partial X_{2}}+\frac{\partial_{2} \theta}{\partial Y_{2}} .
\end{gathered}
$$

It is worth mentioning that some researchers utilized Grashof number $\mathrm{Gr}_{\mathrm{H}}$, instead of Ra, defined as

$$
G r_{H}=\frac{g \beta\left(T_{H}-T_{C}\right) H_{3}}{v_{2}} .
$$

Now dimensionless velocities, on all walls:

- $\mathrm{U}=\mathrm{V}=0$,

dimensionless temperatures:

- $\theta=1$ on hot;

- $\theta=0$ on cold walls. 
Here, $\mathrm{U}$ and $\mathrm{V}$ are non dimensional velocity components; $\mathrm{P}$ is the dimensionless pressure, $\theta$ denotes the dimensionless temperature; and $\mathrm{Ra}$ and $\mathrm{Pr}$ stand for Rayleigh and Prandtl numbers, respectively.

The mean Nusselt numbers are obtained from the relation

$$
\overline{N u}_{H}=\frac{\bar{h} H}{k} .
$$

The steady-state form of the conservation equations in stream function-vorticity form or vorticity-velocity form have been used in some research papers. These formulations are given in Rahimi et al. [15].

\section{NUMERICAL PROCEDURE}

In the present numerical study, natural convection flow of air, having a Prandtl number of 0.72 , in right and isosceles triangular cavities, is considered. For both cases, the meshs on triangular cavities is created by using equilateral triangular elements. The grid size of $60 \times 60$ (3,600 grid points) and, making a total of 3,187 equilateral triangular elements are used for the generation of the mesh to compute of the flow in the right triangular enclosure for aspect ratio of $\mathrm{A}=1.4,528$ elements are utilized for isosceles case for aspect ratio of $\mathrm{A}=0.5$.

Gambit 2.2.30 is utilized for producing and meshing the domain and Fluent 6.0.12 [27] is used to solve the conservation equations. For discretization the finite volume approach is used. Iterations are repeated until the preselected convergence criteria are reached for each conservation equation. In this work, the convergence criteria are chosen as $10^{-10}$. It must be stressed that this value has a significant influence on results. The symmetric or asymmetric flow prevails in the enclosure according to the value of the selected convergence criteria.

\subsection{Grid independency}

In isosceles triangular enclosures, for the aspect ratio of $\mathrm{A}=0.5$, the grids utilized in this study, from coarse to fine grids, have consisted of 1,875, 3,158, 4,528, 7,030 and finally 17,800 equilateral triangular elements. The solutions are acquired by using aforementioned grids at Rayleigh numbers of $10,{ }^{3} 10,{ }^{4}$ and $10^{5}$. Key parameters selected for grid dependency study, that are the horizontal velocity components on symmetry plane and the average Nusselt numbers, are computed with these grids and compared. The grids utilized in the present numerical work are chosen in such a way that the differences in these chosen quantities are always not greater than $1.2 \%$. In this manner, the optimum grid structure yielding the meshfree numerical results is determined to be 4,528 elements grid at $\mathrm{A}=0.5$. The same procedure for grid independent results is applied to right triangular cases.

Furthermore, an additional local quantity, that is the local convective Nusselt numbers $\left(\mathrm{Nu}_{\mathrm{c}}\right)$ for the bottom wall at $\mathrm{A}=0.5$ and $\mathrm{Ra}=10^{5}$ (isosceles case) are calculated by using more refined grid and displayed on the same diagram as shown in Fig. 2. From the abovementioned considerations, the selected grid resolutions are sufficient to produce grid independent results.

\subsection{Code validation}

For the purpose of the code validation, a comparison of several computed key quantities with the available experimental data has been carried out. One of these key quantities is the 


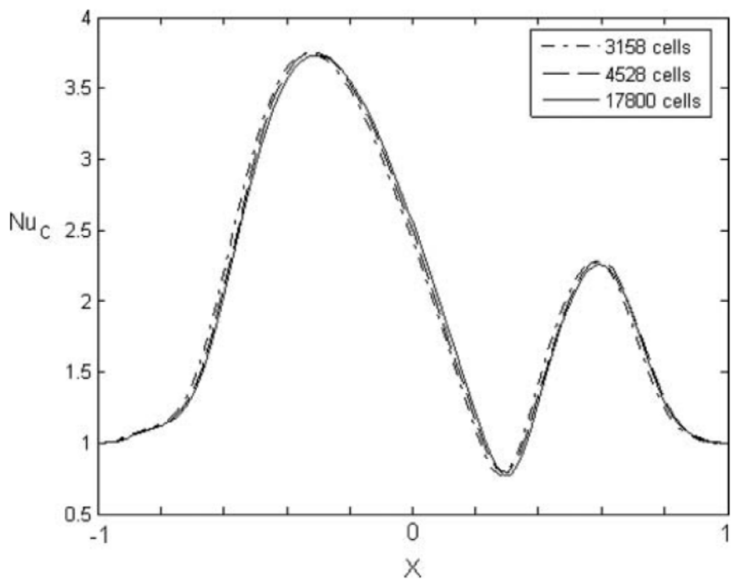

Figure 2: $\mathrm{Nu}_{\mathrm{c}}$ along the base of isosceles triangular enclosure for $\mathrm{A}=0.5$ and $\mathrm{Ra}=10^{5}$ using different grids.
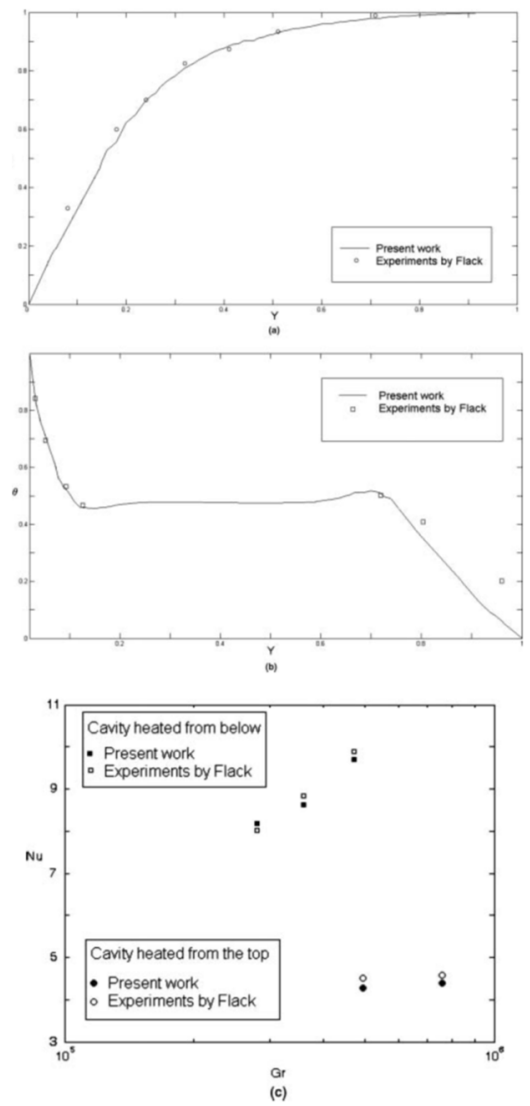

Figure 3: Comparison of the numerical results with experimental data. 
nondimensional temperature variation on the centre-plane at $\mathrm{A}=0.5$. Flack's experimental data are used to compare the numerical results for the corresponding top heating (Fig. 3(a)) and the bottom heating (Fig. 3(b)) in isosceles triangular channels [3]. From Fig. 3(a) it is clearly seen that the temperature nearly constant in the top part of the channel. An excellent agreement is seen between the results. Fig. 3(b) portrays the same quantity, but for the case heating from the bottom. Severe temperature gradients are seen in the vicinity of the top and bottom sections, whereas central section has nearly uniform temperature. In this case the agreement between the results is very good for the bottom part and satisfactory for the top regions. The comparison of the mean Nusselt numbers with experimental data, for the two cases, are depicted in Fig. 3(c). It can be said that the agreement between the results is satisfactory.

\section{NUMERICAL RESULTS AND DISCUSSION}

\subsection{Isosceles triangular enclosures}

In this subsection, streamlines and isotherms are shown for isosceles triangular enclosures. In Fig. 4 the results are plotted the for enclosure having an aspect ratio of $A=0.87,\left(\gamma=60^{\circ}\right)$.
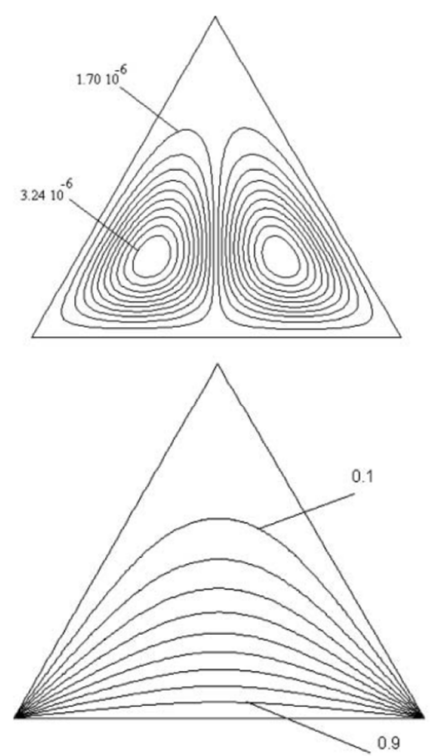

(a)
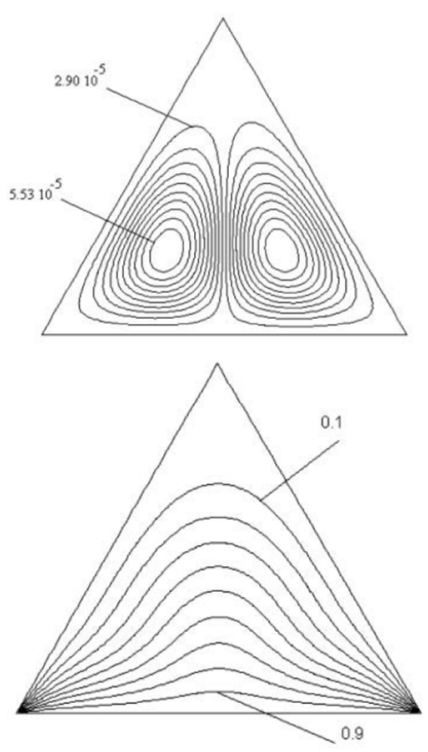

(b)
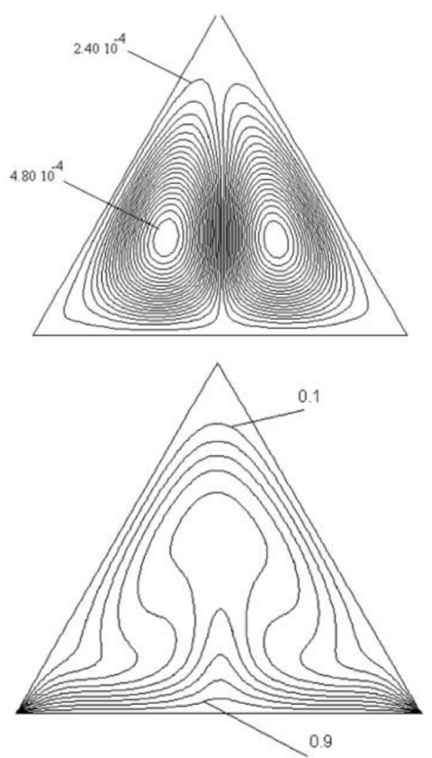

(c)

Figure 4: Streamline and isotherms for $\mathrm{A}=0.87$. (a) $\mathrm{Ra}=10^{3}$; (b) $\mathrm{Ra}=10^{4}$; and (c) $\mathrm{Ra}=10^{5}$.

Completely symmetrical flow structures and isotherms are observed in the enclosures for all Rayleigh numbers investigated. Two symmetric recirculating cells are detected. There are nearly stagnant regions close to the top corner. It must be noted that the areas of the stagnant flow region and cold isothermal region close to the top corner diminish as Rayleigh number increases. Convection effects on the isotherm lines can be clearly seen in Fig. 4(c). Streamlines and isotherms for the aspect ratio of $A=0.5,\left(\gamma=45^{\circ}\right)$, are shown in Fig. 5. 

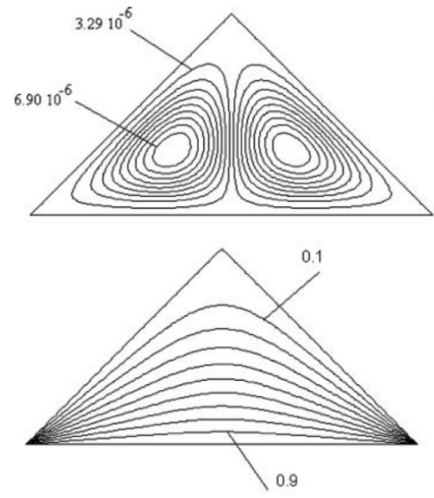

(a)
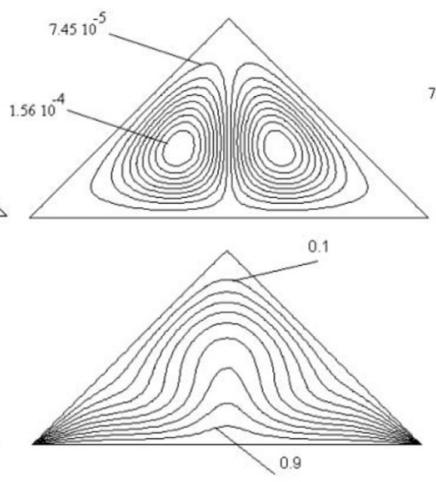

(b)
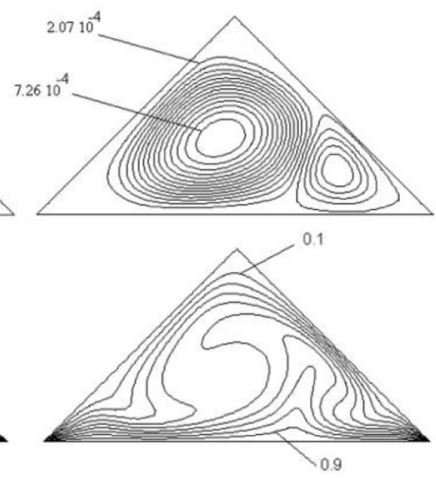

(c)

Figure 5: Streamline and isotherms for $A=0.5$. (a) $\mathrm{Ra}=10^{3}$; (b) $\mathrm{Ra}=10^{4}$; and (c) $\mathrm{Ra}=10^{5}$.

Although the flow is symmetric for $\mathrm{Ra}=10^{3}$ and $\mathrm{Ra}=10^{4}$, asymmetrical flow is observed for $\mathrm{Ra}=10^{5}$. The critical Grashof number $\left(\mathrm{Gr}_{\mathrm{c}}\right)$ is the limit for the symmetric flow. Holtzman et al. [8] noted the value of $\mathrm{Gr}_{\mathrm{c}}=16,200$. (Thus, $\mathrm{Ra}_{\mathrm{c}}=1.15 \times 10^{4}$ ). For this reason, asymmetric flow occurs in the channel for $\mathrm{Ra}=10^{5}$ as seen in Fig. 5(c). The areas of the stagnant flow region and cold isothermal region close to the top corner are considerably diminished for this aspect ratio. One main (central) and one small secondary cell are seen for $\mathrm{Ra}=10^{5}$ in Fig. 5(c). There is only one thermal plume arising from the base is observed.

It must be stressed here that if the convergence criteria used had not been sufficiently small, then symmetric solutions would have been acquired in the enclosures, for also at $\mathrm{Ra}=10^{5}$. It is crucial that this parameter should be selected sufficiently small, especially for the energy equation not to affect the solutions. It is worth mentioning that some researchers obtained completely symmetric solutions about the mid-plane, although no assumption about symmetry is prescribed. The reason for this may be attributed to the convergence criteria that were not prescribed sufficiently small in the numerical solutions.

The streamlines and isotherms for the aspect ratio $\mathrm{A}=0.29\left(\gamma=30^{\circ}\right)$ are displayed in Fig. 6. Now $\mathrm{Gr}_{\mathrm{c}}=8,930$ for this aspect ratio. This is equivalent to a value of $\mathrm{Ra}_{\mathrm{c}}=6.34 \times 10^{3}$. Two symmetric cells, now filling almost the entire cavity, are only seen for $\mathrm{Ra}=10^{3}$ (Fig. 6(a)). On the other hand, the flows are asymmetric for both $\mathrm{Ra}=10^{4}$ and $\mathrm{Ra}=10^{5}$. For $\mathrm{Ra}=10^{4}$, two rotating cells are observed, one main cell grows in size and migrates from the corner to the centre while the second one keeps its position but diminishes in size (Fig. 6(b)). One hot thermal plume arising from the hot bottom is seen in the corresponding isotherm contours. For $\mathrm{Ra}=10^{5}$, four rotating cells are detected. In this case, there are two hot thermal plumes in the isothermals (Fig. 6(c)). These cells are responsible for the increase of the total heat transfer in the cavity. The left plume is bigger than the right one. As the aspect ratio diminishes, the stagnant regions and cold isothermal areas shrink.

\subsection{Right triangular enclosures}

For the right triangular enclosure, the prescribed boundary conditions are as follows: the bottom is hot, hypotenuse is cold, and vertical wall is adiabatic. This case resembles the complete isosceles triangular enclosure divided by an adiabatic wall at the vertical symmetry 

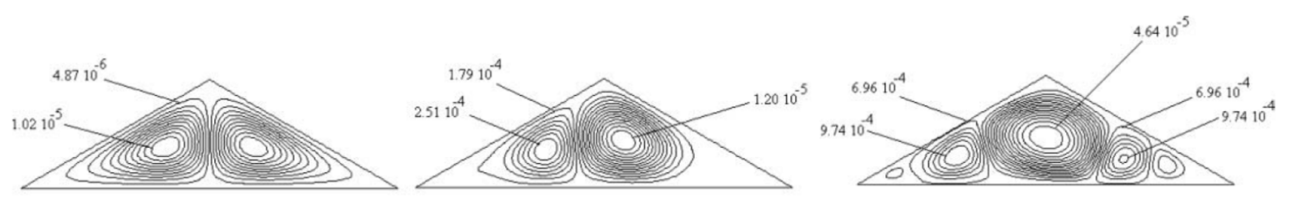

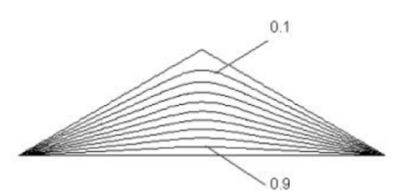

(a)

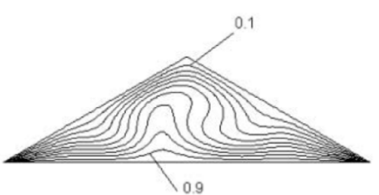

(b)

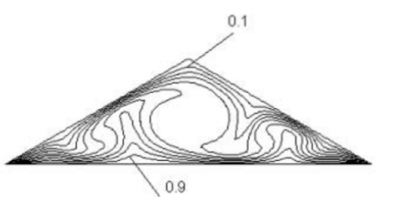

(c)

Figure 6: Streamline and temperature distributions for $A=0.29$.
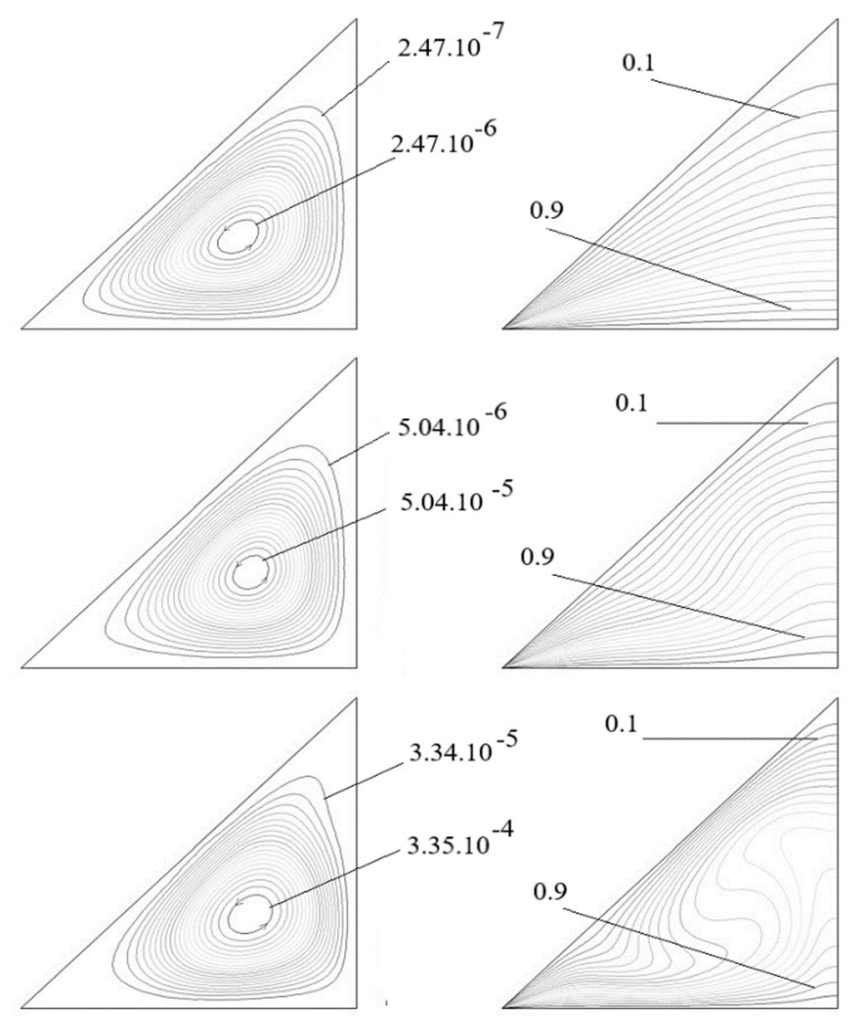

Figure 7: Streamline and isotherms contours in the right triangular enclosure for $\mathrm{A}=1$.

plane by half. The streamlines and isotherms for the aspect ratio $\mathrm{A}=1$ are shown in Fig. 7. One clockwise rotating cell is seen for all the Rayleigh numbers. The streamlines and isotherm contours of Fig. 7(a) and (b) are very similar to their counterparts of Fig. 5(a) and (b). But with these boundary conditions it is obviously not possible to detect asymmetric flow structures in the cavity. 


\subsection{Heat transfer}

The overall heat transfer capabilities of the triangular enclosures can be evaluated by examining the average convective Nusselt numbers $\mathrm{Nu}_{\mathrm{c}, \text { avg }}$ of the hot wall. The local Nusselt numbers are unbounded at the corners where the hot and cold walls meet. For this reason, direct integration of the local Nusselt numbers would yield erroneous results. In these regions, the fluid is stagnant and heat transfer is conduction dominant. In order to avoid unbounded heat transfer in these regions, a convective Nusselt number, $\mathrm{Nu}_{\mathrm{c}}$, must be used. $\mathrm{Nu}_{\mathrm{c}}$ is the ratio of $\mathrm{Nu}$ calculated for a given $\mathrm{Ra}$ to $\mathrm{Nu}$ calculated for conduction case. It is worth to mentioning that $\mathrm{Nu}_{\mathrm{c}}$ asymptotically converges to unity for low $\mathrm{Ra}$. $\mathrm{Nu}_{\mathrm{c}}$ on the hot bottom wall are calculated for $\mathrm{A}=0.87,0.5$ and 0.29 . By using these local convective Nusselt numbers $\mathrm{Nu}_{\mathrm{c}}, \mathrm{Nu}_{\mathrm{c}, \text { avg }}$ are found depending on $\mathrm{A}$, and presented in Table 1.

Table 1: Numerically calculated values of $\mathrm{Nu}_{\mathrm{c}, \mathrm{avg}}$.

\begin{tabular}{|c|c|c|c|c|}
\hline $\mathbf{A}$ & $\mathbf{R a}=\mathbf{1 0}^{\mathbf{3}}$ & $\mathbf{R a}=\mathbf{1 0}^{\mathbf{4}}$ & $\mathbf{R a}=\mathbf{0 . 7 1} \times \mathbf{1 0}^{\mathbf{5}}$ & $\mathbf{R a}=\mathbf{1 0}^{\mathbf{5}}$ \\
\hline 0.87 & 1.0 & 1.02 & & 1.78 \\
\hline 0.5 & 1.0 & 1.20 & 1.88 & 1.99 \\
\hline 0.29 & 1.0 & 1.30 & & 2.48 \\
\hline
\end{tabular}

It must be noted that Holtzman et al. [8] indicated a value of $\mathrm{Nu}_{\mathrm{c}, \mathrm{avg}}=1.80$ for $\mathrm{A}=0.5$, and for $\mathrm{Gr}=10^{5}$ (thus, $\mathrm{Ra}=0.71 \times 10^{5}$ ). The corresponding numerical results of the present work for $\mathrm{Nu}_{\mathrm{c}, \text { avg }}$ is to be 1.88 (only about $4.5 \%$ great).

The average convective Nusselt numbers increase with the Rayleigh numbers for each aspect ratios $\mathrm{A}$, as expected. As the aspect ratio diminishes, the increase of the average convective Nusselt numbers (heat transfer) with the Rayleigh numbers are more pronounced. For $\mathrm{A}=0.87$, the increase of $\mathrm{Nu}_{\mathrm{c}, \text { avg }}$ with the growth of Ra from $10^{3}$ to $10^{5}$ is $78 \%$; whereas for $\mathrm{A}=0.29$ it is as much as $148 \%$. This is due to the multicellular flow structures and strong convective motion occurred.

\section{CONCLUSIONS}

In this work, a numerical simulation of convective flow in right and isosceles triangular enclosures are carried out. The following conclusions may be drawn from this study.

At $\mathrm{Ra}=10^{3}$ two symmetric counter-rotating cells and symmetric isotherms are seen for in the isosceles enclosure for all aspect ratios. At lower Rayleigh numbers, it can be inferred from the shape of the isotherms that conduction is the dominant mode of heat transfer.

As Ra numbers increases, convective motion in the cavity also increases. Depending on the aspect ratio and $\mathrm{Ra}$ numbers, there is a critical $\mathrm{Ra}_{\mathrm{c}}$ numbers, which has a paramount influence of the flow in the cavity. Completely symmetric flows occur in the cavity if $\mathrm{Ra}<\mathrm{Ra}_{\mathrm{c}}$, whereas asymmetric flows prevails if $\mathrm{Ra}>\mathrm{Ra}_{\mathrm{c}}$. Symmetry breaking pitchfork bifurcations and multi cellular structures are seen in the cavity. These are responsible for the increase of heat transfer.

The selection of convergence criteria for the conservation equations is of vital importance. The numerical solutions depended on these criteria like grid independency. If the convergence criteria are not sufficiently small, erroneous symmetric numerical solutions will produce. It is impossible to detect the real asymmetric solutions by using improper convergence criteria (i.e. not sufficiently small).

Symmetry assumption is not suitable for these problems. It is also impossible to detect the real asymmetric solutions by using symmetry condition. 
Use of convective Nusselt number is more suitable because of the singularities occurred on the corners.

As the aspect ratio diminishes, the increase of the average convective Nusselt numbers (heat transfer) with the Rayleigh numbers are more pronounced. This is due to the multicellular flow structures and strong convective motion occurred in the triangular cavities at low aspect ratios and high Rayleigh numbers.

\section{ACKNOWLEDGEMENT}

The author would like to express his sincere thanks to the referees for comments which improves the quality of the work.

\section{REFERENCES}

[1] Flack, R.D., Velocity measurements in two natural convection air flows using a laser velocimeter. Journal of Heat Transfer, 101, pp. 256-260, 1979.

[2] Flack, R.D., Konopnicki, T.T. \& Rooke, J.H., The measurement of natural convective heat transfer in triangular enclosures. Journal of Heat Transfer, 101, pp. 648-654, 1979.

[3] Flack, R.D., The experimental measurement of natural convection heat transfer in triangular enclosures heated or cooled from below. Journal of Heat Transfer, 102, pp. 770-772, 1980.

[4] Akinsete, V.A. \& Coleman, T.A., Heat transfer by steady laminar free convection in triangular enclosures. International Journal of Heat and Mass Transfer, 25(7), pp. 991-998, 1982.

[5] Poulikakos, D. \& Bejan, A., The fluid mechanics of an attic space. Journal of Fluid Mechanics, 131, pp. 251-269, 1983.

[6] Salmun, H., Convection patterns in a triangular domain. International Journal of Heat and Mass Transfer, 38(2), pp. 351-362, 1995.

[7] Salmun, H., The stability of a single-cell steady-state solution in a triangular enclosure. International Journal of Heat and Mass Transfer, 38(2), pp. 363-369, 1995.

[8] Holtzman, G.A., Hill, R.W. \& Ball, K.S., Laminar natural convection in isosceles triangular enclosures heated from below and symmetrically cooled from above. Journal of Heat Transfer, 122, pp. 712-717, 2000.

[9] Lei, C., Armfield, S.W. \& Patterson, J.C., Unsteady natural convection in a water-filled isosceles triangular enclosure heated from below. International Journal of Heat and Mass Transfer, 51, pp. 2637-2650, 2008.

[10] Kent, E.F., Laminar natural convection in isosceles triangular roofs in wintertime conditions. Heat Transfer Engineering, 31(13), pp. 1068-1081, 2010.

DOI: $10.1080 / 01457631003640339$.

[11] Kent, E.F., Numerical analysis of laminar natural convection in isosceles triangular enclosures for cold base and hot inclined walls. Mechanics Research Communications, 36, pp. 497-508, 2009.

[12] Kent, E.F., Asmaz, E. \& Ozerbay, S., Laminar natural convection in right triangular enclosures. Heat and Mass Transfer, 44, pp. 187-200, 2007.

[13] Wang, Q., Li, W., Chen, Z. \& Kukulka, D.J., Numerical analysis on natural convection in various enclosures. Numerical Heat Transfer, Part A: Applications.

DOI: $10.1080 / 10407782.2019 .1701347$.

[14] Triveni, M.K. \& Panua, R., Numerical analysis of natural convection in a triangular cavity with different configurations of hot wall. International Journal of Heat and Technology, 35, pp. 11-18, 2017. DOI: 10.18280/ijht.350102. 
[15] Rahimi, A. Sae, A.D., Kasaeipoor, A.D. \& Malekshah, E.A., A comprehensive review on natural convection flow and heat transfer. International Journal of Numerical Methods for Heat and Fluid Flow, 29(3), pp. 834-887.

[16] Bairi, A., Zarco-Pernia, E. \& Garcia de Maria, J.M., A review on natural convection in enclosures for engineering applications. The particular case of parallelogrammic diode cavity. Applied Thermal Engineering, 63, pp. 304-322, 2014.

[17] Das, D., Roy, M. \& Basak, T., Studies on natural convection within enclosure of various (non-square) shapes: A review. International Journal of Heat and Mass Transfer, 106, pp. 356-406, 2017.

[18] Oztop, H.F., Estelle, P., Yan, W.M., Al-Salem, K., Orfi, J. \& Mahian, O., A brief review of natural convection in enclosures under localized heating with and without nanofluids. International Communications in Heat and Mass Transfer, 60, pp. 37-44, 2015.

[19] Kamiyo, O.M., Angeli, D., Barozzi, G.S., Collins, M.W., Olunloyo, V.O.S. \& Talabi, S.O., A comprehensive review of natural convection in triangular enclosures. Applied Mechanics Reviews, 63, 060801-13, 2010.

[20] Saha, S.C. \& Khan, M.M.K., A review of natural convection and heat transfer in atticshaped space. Energy and Buildings, 43, pp. 2564-2571, 2011.

[21] Aich, W., CFD analysis of three dimensional natural convection and entropy generation in triangular cavity with inserted isothermal heater. University of $\mathrm{Ha}$ 'ilJournal of Science, 1(1), pp. 29-40, 2018.

[22] Cui, H., Xu, F., Saha, S.C. \& Liu, Q., Transient free convection heat transfer in a section-triangular prismatic enclosure with $\mathrm{n}$ different aspect ratios. International Journal of Thermal Sciences, 139, pp. 282-291, 2019.

[23] Hease, P.M. \& Teubner, M.D., Heat exchange in an attic space. International Journal of Heat and Mass Transfer, 45, pp. 4925-4936, 2002.

[24] Ridouane E.H., Campo, A. \& Hasnaoui, M., Turbulent natural convection in an airfilled isosceles triangular enclosure. International Journal of Heat and Fluid Flow, 27, pp. 476-489, 2006.

[25] Talabi, S.O., Olunloyo, V.O.S., Kamiyo, O.M., Collins, M.W. \& Karayiannis T.G., Flow field and Reynolds stress distribution in low turbulence natural convection in a triangular cavity. Proceedings of the 5th International Symposium on Turbulence, Heat and Mass Transfer, pp. 511-514, 2006.

[26] Gray, D.D. \& Giorgini, A., The validity of the Boussinesq approximation for liquids and gases. International Journal of Heat and Mass Transfer, 19, pp. 545-551, 1976.

[27] Fluent 6.0.12, Fluent Inc.: Lebanon, NH, 2001. 